Portland State University

PDXScholar

11-26-1985

\title{
Cultural Characteristics of Learning and Perceptual Skills of Southeast Alaskan Native 5-Year-Olds
}

Thomas J. Turkon

Portland State University

Follow this and additional works at: https://pdxscholar.library.pdx.edu/open_access_etds

Part of the Child Psychology Commons, and the Cognitive Psychology Commons Let us know how access to this document benefits you.

\section{Recommended Citation}

Turkon, Thomas J., "Cultural Characteristics of Learning and Perceptual Skills of Southeast Alaskan Native 5-Year-Olds" (1985). Dissertations and Theses. Paper 3526.

https://doi.org/10.15760/etd.5410

This Thesis is brought to you for free and open access. It has been accepted for inclusion in Dissertations and Theses by an authorized administrator of PDXScholar. Please contact us if we can make this document more accessible: pdxscholar@pdx.edu. 
AN ABSTRACT OF THE THESIS OF Thomas J. Turkon for the Master of Science in Psychology presented November 26, 1985.

Title: Cultural Characteristics of Learning and Perceptual Skills of Southeast Alaskan Native 5-Year-01ds.

APPROVED BY MEMBERS OF THE THESIS COMMITTEE:

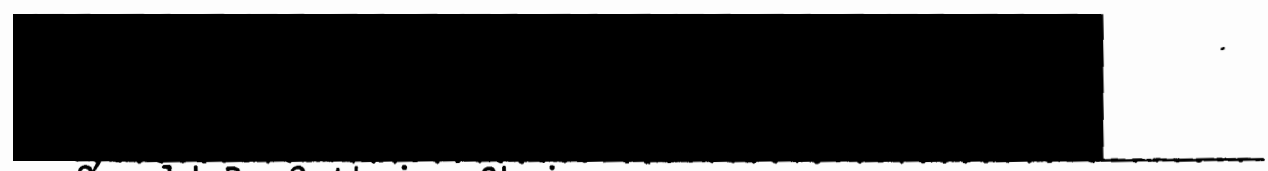

Gerald D. Guthrie, Chair

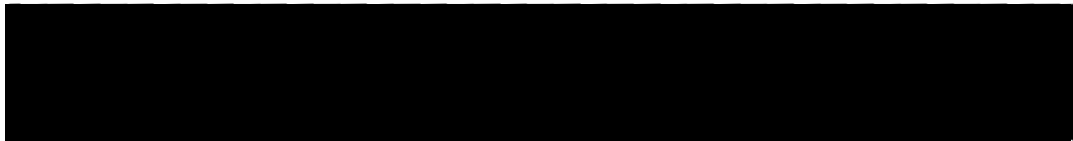

Ronald E. Smith

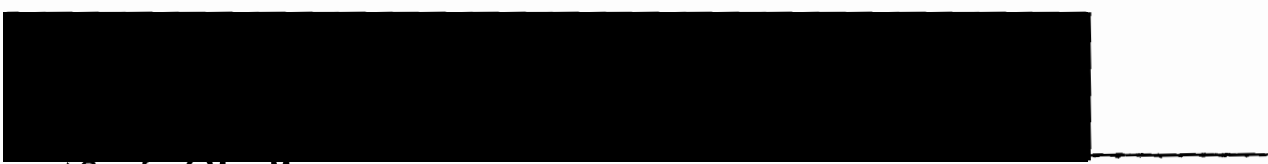

'sperdM. Manson

This study examined the use of cognitive skills by 5 -year-old Alaskan Native children on a standardized testing instrument. The Wechsler Preschool and Primary Scales of Intelligence (WPPSI) were administered to 23 boys and 17 girls of predominantly Tlingit, Tsimshean, and Haida ancestry. A standardized parent interview was used to cullect bio-demographic data. Mean scores for the sample displayed significant differences between the Performance and Verbal scales, with the strongest performance in the Spatial subtests, and lowest in the Sequential subtests. Scores were significantly associated with variables representing culture-specific self identity and behavior, but were most strongly associated with family size. Factor Analysis suggested a distinct three factor structure consisting of (1) a Performance-Spatial, 
(2) a Verbal-Semantic, and (3) a Sequential factor. Variability in the use of cognitive skills, non-verbal behavior, and selective attention are viewed as unique cultural adaptations which can impede interethnic communication, creating negative outcomes in the education of American Indian and Alaskan Native children. 
CULTURAL CHARACTERISTICS OF LEARNING

AND PERCEPTUAL SKILLS OF SOUTHEAST

ALASKAN NATIVE 5-YEAR-OLDS

by

Thomas J. Turkon

A thesis submitted in partial fulfillment of the requirements for the degree of

MASTER OF SCIENCE

in

PSYCHOLOGY

Portland State University

1985 
TO THE OFFICE OF GRADUATE STUDIES AND RESEARCH:

The members of the Committee approve the thesis of Thomas $J$. Turkon presented November 26, 1985.

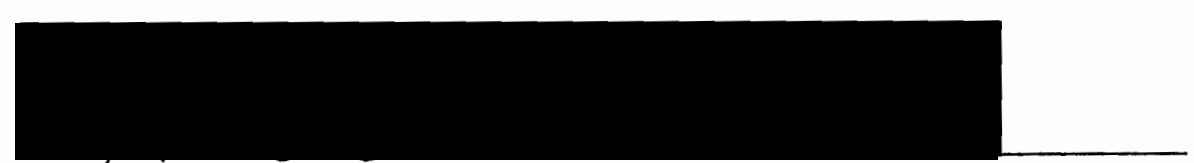

Gérald D. Guthrie, Chair

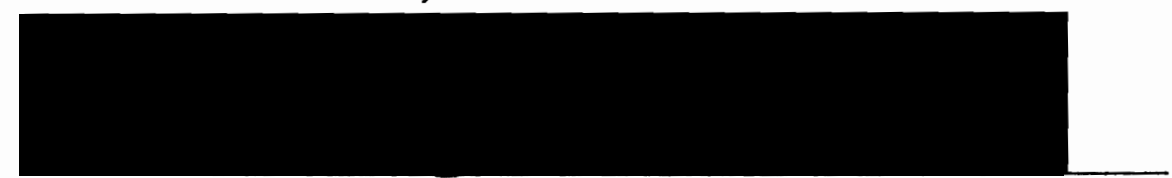

Ronald E. Smith

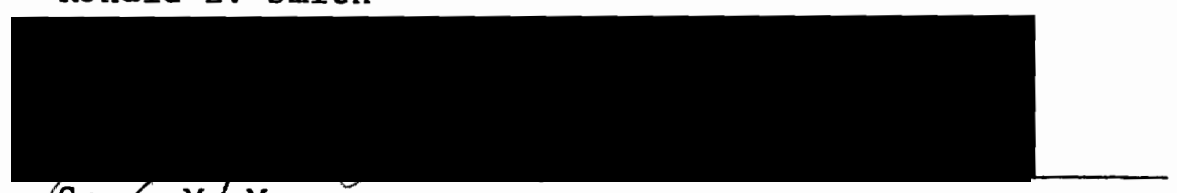

¿Spezo M. Manson

APPROVED :

Roger D. Jennźngs, Head, Department of Psychology

Jim F. Hglath, Dean of Graduate Studies and Research 
RUTH, BOBBY, AND CARY 


\section{ACKNOWLEDGEMENTS}

I would like to express heartfelt thanks to those who so generously gave their time and support in a manner which made this project possible. Damian A. McShane provided the initial support and encouragement for the design of this study. Daniel L. Wood provided endless consultation on subtle and complex theoretical, methodological, and data management problems. The interest and desire to investigate were inspired by members of the Portland State University faculty, most notably, Ronald E. Smith, who lent his years of studied insight into the use of psychological testing instruments, Gerald D. Guthrie, Spero M. Manson, James A. Paulson, David Urench, Hugo Maynard, and Janice K. Haaken. A focus on cultural sensitivity issues was provided early on by Terry Cross of the Northwest Indian Child Welfare Institute at PSU.

Indispensable support and assistance in Alaska were the contribution of Edward K. Thomas, Georgia Finau, Dolly Jensen, and Robert \& Tina Demmert in Ketchikan, and Harris Atkinson, Jr., Shirley Turner, Margaret Bolton, and Reverend William Kallapa in Metlakatla.

My wife Ruth shared her detailed knowledge of Southeast Alaska along with her professional expertise in speech communication and counseling in a manner which allowed this project to be culturally sensitive and relevant to the work of many capable professionals in the region. Special thanks are due to Ruth and Bobby for their patience, support, and encouragement over many months of "family preoccutation" with this project. 


\section{TABLE OF CONTENTS}

PAGE

ACKNOWLEDGEMENTS ...................... iv

LIST OF TABLES ...................... . . . . . vi

LIST OF FIGURES .................. . . . . vii

CHAPTER

I INTRODUCTION ........................ 1

Assessment of Children's Intellectual Skills 7

II METHOD ................ 13

Subjects.............. 13

Procedure ............. . . 14

III RESULTS .................... . . . 16

Score Data.............. 16

Parent Interview Data ........ 20

IV DISCUSSION................... 29

Cognitive Factor Structure of Southeast

Alaskan Native 5 -Year-01ds ..... 35

Conclusion ............. . . . 40

NOTES ............................. 44

BIBLIOGRAPHY . . . . . . . . . . . . . . . . . 45

APPENDIX

Parent Consent and Interview Forms ........ 


\section{LIST OF TABLES}

TABLE

PAGE

I Mean IQ Scores, Standard Deviations, Medians \& Ranges for Study Sample $(\mathrm{N}=40)$. . . . . . . . . . .

II Means of Subtests Recategorized According to Bannatyne

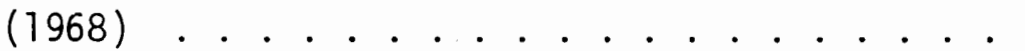

II Factor Structure (Correlation Coefficients) Derived

From Principle Component Analys is with Oblique Rotation................

III-A Means of Subtests Recategorized According to the Observed Three Factor Solution . . . . . . .

IV Subtest Score Means which Differed Significantly

$(p<.05)$ between Independent Child Indian Blood Quantum Groups (N=40) . . . . . . . . .

V Mean Classified Scores for Independent Child Indian Blood Quantum Groups and Significance Levels of Differences ........... . . 23

VI Component Subtests of Factor Analytic Solutions from Kaufman (1975) WISC-R Results and the present. Study of Southeast Alaskan Native WPPSI Results 


\section{LIST OF FIGURES}

FIGLRE

PAGE

1. Percent of Words recalled as a Function of Syntactic and Semantic Structure ............ 


\section{CHAPTER I}

\section{INTRODUCTION}

The transmission from one generation to the next of the social behavior characteristic of a cultural group involves the passing on of complex patterns or mixes of behavioral and perceptual strategies through the process of socialization. The relative balance of non-verbal/verbal/perceptual integration which characterizes the social behavior and selective attention of members of a distinct cultural group is a product of inheritance, and socio-cultural learning variables which interact over many scores of generations to produce complex human culture. Wilson (1980) has said that social organization is the class of phenotypes furthest removed from the genes, derived jointly from the behavior of individuals and the demographic properties of the population, both of which are highly synthetic. The process by which such optimization of organism-environment relationships is achieved is complex and not well understood, but does serve to effectively organize the cooperative tendencies of social groups in unique and adaptive ways.

Early childhood learning in humans is highly complex and varied. It is, however, primarily social and involved with a developing sensitivity to social cues. Thus, Erickson (1981) 
describes early childhood as a time of Sociocentricity rather than Egocentricity, during which the child is rapidly learning through experimentation with the participation structures of social interaction. In each culture, there exists a persistent structure to social interaction which involves a unique mixture of verbal and non-verbal communicative cues with normative expectations for their use. These participation structures are among the significant set of stimuli which constitute processes of socialization within the family during infancy and early childhood. Such a mixture would be expected to have a measurable impact upon the development of selective attention and cognitive-perceptual (or associative) skills.

Luria (1970) has proposed a functional view of cognitive processes, describing them as systems of functions, comparable to Piagetian concepts of operations (Das \& Jarman, 1979). The functional systems proposed by Luria are Arousal, Coding, and Planning. Arousal is an emotional system involving conditioned and innate response patterns and is localized in the subcortical areas of the brain. Coding involves strategies for the storage, access, and synthesis of information while Planning involves the purposive utilization of information in goal directed activity. The process of Coding can be shown to involve two distinct methods of making associations. These were described by Das and Jarman (1979) as Simultaneous (spatial-holistic) processing, and Succesive (1inear-sequential) processing. Snart (1978) factor analyzed scores on the target tests of Simultaneous and Successive 
processes along with scores on deep and shallow levels of processing recall tasks (Craik \& Tulving, 1975) for children in the age groups of 6,11 , and 17 years. In the levels of processing tasks, subjects attempted to recall words following orienting questions requiring them to attend to either the shallow (physical) features or the deep (semantic meaning) features of the word. Three factors emerged within all age groups and were labeled Simultaneous, Successive, and Memory. Physical recall loaded only on the Memory factor for all age groups. Semantic recall, however, loaded primarily on the Memory factor for 6-year-01ds, the Successive factor for 11-year-01ds, and on the Simultaneous factor for 17-year-01ds. Clearly, children were found to be employing different cognitive strategies at different ages on the Semantic tasks. The findings of factor dominance were not exclusive of the other factors which had secondary loadings. Das and Jarman (1979) point out that such factors represent optional processes or strategies for dealing with information and orienting to problems, and that they are used in concert and in different ways by individuals and groups. The developmental nature of cognitive skills involved in semantic processing is further illustrated by a study which measured recall of sentences which carried (1) semantic and syntactic correctness, (2) syntactic correctness with no semantic meaning, and (3) neither syntactic nor semantic order (Frasure \& Entwisle, 1973). Examples of the three types of sentences used are as follows: 
Semantic/Syntax: Bears steal honey from the hive.

Syntax on1y: Trains steal elephants around the house.

Scrambled: $\quad$ From shoot highways the passengers mothers.

The differential recall at four ages were as shown in Figure 1 .

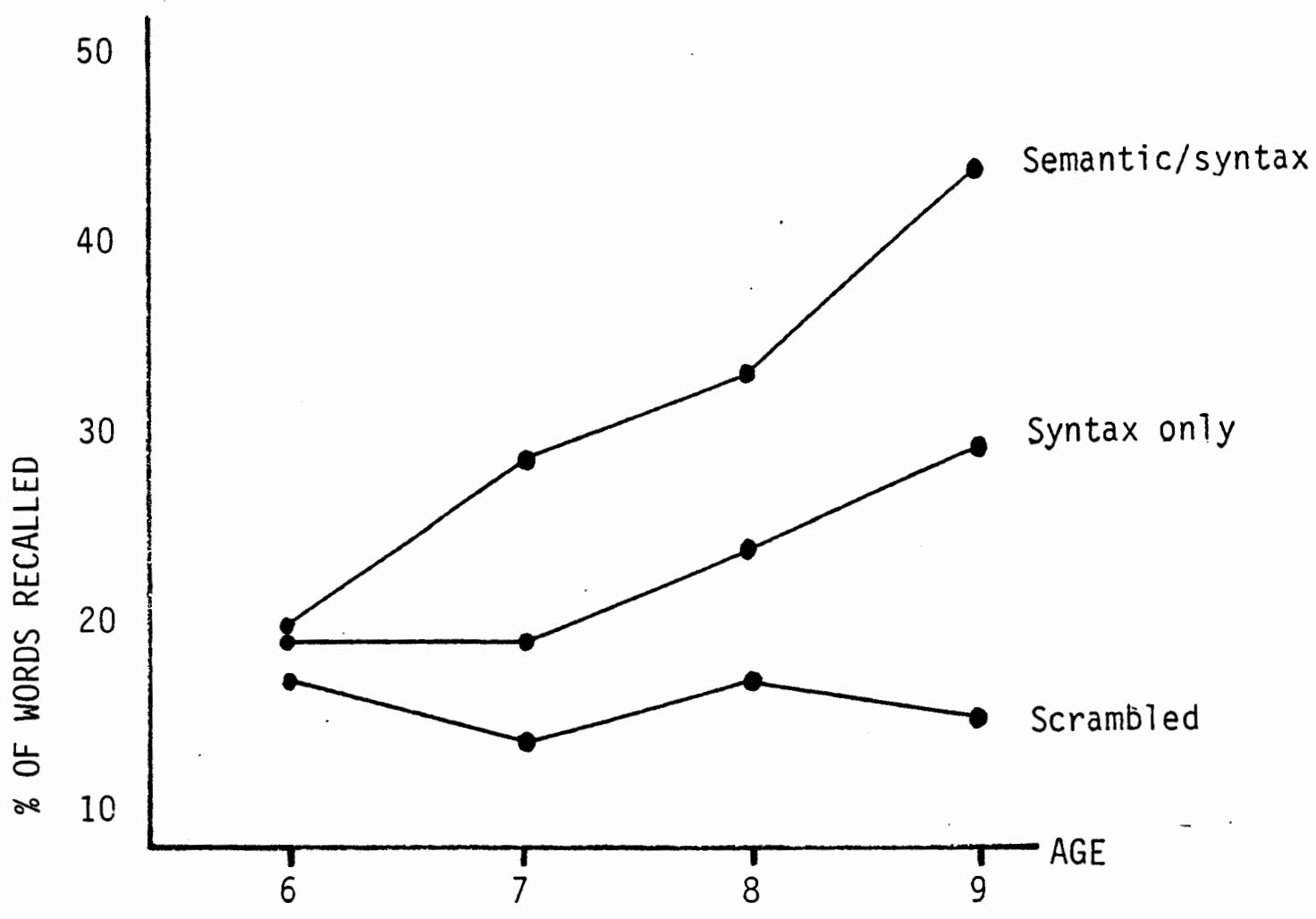

Figure 1. Percent of words recalled as a function of syntactic and semantic structure (Frasure \& Entwisle, 1973).

Deep processing, in these children, evidently involves contextual relevancy or association of input with learned 
information in a manner that progressively (with age) involves Successive coding skills and later becomes predominantly characterized by Simultaneous coding skills. Such a progression may be a function of a culturally characteristic socialization process which focuses attention upon form, phonemics, and letter/word sequential relationships as the first step in building and emphasizing technical language competency.

Scollon and Scollon (1981) have provided a sociolinguistic description of Thematic Abstraction, an Athabaskan cognitive orientation which is characterized in young children by non-intrusive observation of others and verbal communication using metonyms to refer to and construct themes which are mutually understood by members of the socio-cultural group. This system of metonymic referencing is used to address thematic perceptions which are highly contextualized within present time and social circumstances. These and other features constitute a discourse pattern which, whether spoken in Athabaskan or English, is oriented to behaviors and actions which vary in complex meaning as a function of speaker inflections and social context. Discourse patterns in European cultures, by contrast, are linear and more highly verbal-content oriented. The European emphasis on verbal presentation focuses upon content of communication without social context (or rather, restricts context to the formal referential content). Scollon and Scollon (1981) maintain that the orientation to decontextualized content, like the 
orientation to Thematic Abstraction, begins in infancy and progresses through the period of early childhood acquisition of social and communicative skills.

The development of selective stimulus preference, like the development of linguistic and cognitive coding skills, has been shown to vary across geocultural groups in response to the learning demands which characterize the group. Western children respond to the cultural demands for language literacy with a dramatic shift in selective attention at about age 5 , when the salience of visual shape and form suddenly increase, eclipsing the previously dominant preference for color. Islamic children in Nigeria who do not learn to read, but are required to memorize and recite sections of the Koran, show no such shift in selective attention form early childhood to adolescence (Suchman, 1966, Suchman \& Trabasso, 1966). Krywaniuk and Das (1976) demonstrated the efficacy for school learning (among Canadian Indian children) of specific combinations of simultaneous and successive coding skills, suggesting that learning success depends heavily on a certain pattern of aptitudes rather than on a single one.

Assessment instruments such as the Wechsler Intelligence Scales and the Woodcock Johnson Psychoeducational Battery are designed on the assumption that schools do a reasonably good job of creating learning, and attempting to provide a means for assessing certain critical skills which are associated with "normal" learning for the majority of children. 
Assessment of Children's Intellectual Skills

The Wechsler Intelligence Scales for Children - Revised (WISC-R), and the Wechsler Preschool and Primary Scales of Intelligence (WPPSI) are well standardized psychometric tests which have gained wide acceptance in educational and clinical settings. For the majority of North American children, the subtests composing these scales have been demonstrated to have high degrees of statistical reliability and validity in predicting specific academic skill areas in which a child is likely to experience learning success or difficulty. Given that a child is adequately motivated to give an optimal performance and a valid protocol is obtained, the various subtests provide a good, general screening of a child's competency in a number of task situations. The subtests call into play a variety of intellectual skills and previously learned concrete and abstract knowledge. The score data, and other relevant information regarding the child's ongoing level of functioning, enable an estimation of specific skills which he or she may be underusing or perhaps overusing in a spontaneous and habitual manner.

The Wechsler Intelligence Scales were designed for assessment within the context of a socio-cultural milieu represented by the standardization groups. Performance standards for each age group of the WPPSI were established by administering the test to 1,200 children who were tested between October of 1963 and May of 1966. The sample included white and nonwhite children in the ratios found in the 1960 U.S. Census 
(Wiechsler, 1967). Al1 non-white (minority) children composed 14 percent of the standardization sample.

The purpose of these tests is to provide data for making inferences regarding levels of competency in specific skill areas deemed important within contemporary American society. Sattler (1982) points out that intelligence tests focus primarily on problem solving and abstract abilities, and deal with only a certain part of the broad spectrum of abilities or competencies which can be labeled "intelligence." Scollon and Scollon (1981) discuss the centrality of a particular view of reading and writing to education in America as reflective of a cognitive orientation which may be alien to cultural groups with a traditionally different orientation. Cole and Bruner (1971) discuss the effect of "knowing a rule" or "having a competence" in terms of social adaptiveness as defined within a cultural context. That such rules and competencies vary greatiy from one socio-cultural group to another has been observed in numerous studies in ethnography and cross-cultural psychology. To the extent that such differences (as well as similarities) are recognized and accepted by members of differing socio-cultural groups, interethnic communication (and cooperative, shared objectives) are both possible and mutually beneficial. The alternative to mutual understanding is stereotyping, by which one explains the incongruous behavior of another in terms which are comprehensible only within one's own cultural experience (Scollon \& Scollon, 1981). 
The implicit belief that one's culture is superior to all others (ethnocentrism) rests upon such stereotyping.

Common settings for cultural interfacing within a pluralistic society include the workplace, government, and the educational system. In the case of the latter, use of tests such as the Wechsler Scales for placement and planning purposes may involve important questions of validity. An example is provided by the work of Henderson and Rankin (1973) with Mexican-American 5-year-olds. For third grade scores on the Metropolitan Reading Test, predictive validity based upon earlier WPPSI scores was poor $(r=.27)$.

A number of investigators have employed factor analytic procedures with the Wechsler subtests and other testing instruments in order to better understand cognitive coding, content, and process. Kaufman (1975), employing factor analys is on subtest data from the WISC-R standardization group, identified three factors common to all six-month age groups from 6 to 16 years. Two of these factors, Verbal Comprehension and Perceptual Organization, correspond to the original Verbal and Performance Scales. The third factor, labeled Freedom From Distractability, was formed by consistent intercorrelations among the three subtests known as Arithmetic, Digit Span, and Coding. Bannatyne (1968) described a similar scheme for recategorization of Weshsler subtest scores which has proved useful in the identification of learning disabilities. Within Bannatyne's 
framework, the same three subtests identified with Kaufman's Freedom From Distractability factor form a category which is used to assess sequential processing skills. These three subtests are considered to require the use of a linear-sequential stepwise process, or series of abstract, conceptually related operations, executed in a planful and (necessarily) consistent manner. Such goal-directed cognitive behavior requires a learning of competency in an abstract schema and involves sustained selective attention (concentration) as well. Sequential coding (learned, abstract association skills), and Freedom From Distractability (directed selective attention) are interactive determinants of performance on these "third factor" subtests. McShane and Plas (1982a) studied WISC, WISC-R and WPPSI subtest scores recategorized according to the Bannatyne (1968) scheme. They observed an Indian Subscale pattern which differed from learning disabled groups and which was characterized by Spatial performance significantly higher than Sequential performance which exceeded Conceptual and Acquired Knowledge performances. The manifestation of this scoring pattern among Indian children appeared to be linked to traditional cultural experience. In the comparatively small early childhood (WPPSI) sample, the Spatial performance scores averaged a full standard deviation above the standardization group mean, suggesting superior development of Spatial processing skills in young Indian children. Indian students frequently display a significant 
elevation of the Performance IQ over the Verbal IQ. This

difference may average twenty-five points among traditionally oriented Indian children, particularly those who are bilingual. McShane and Plas (1984) believe that an eight to nineteen point discrepancy can be considered typical for the Indian child.

Such a performance pattern may be reflective of a cognitive orientation which is somewhat less than adaptive in the context of most modern schools which place considerable emphasis on verbal and sequential/analytic skills. Caucasian children may have a certain cultural predisposition to such skills while native children are predisposed culturally to a different set of skills. The long run probability of the Indian child's academic success in standard U.S. educational settings may be diminished by the tendency of educators to address learning in a manner which ignores the Indian child's most notable strengths, demanding attention in areas of cognition and perception which may be unfamiliar and/or incongruent. The young Indian child appears to be predisposed to a different type of cognitive integration, or systems for extending and reinterpreting information on the basis of perception and meaning.

While validity problems have been acknowledged, the Wechsler Tests are considered to be a significant improvement over the more Traditional Stanford Binet, because of the equal weight given to non-verbal (Performance) skills. This study aimed to provide some assessment of the usefulness and 
interpretability of the WPPSI as it applies to an Alaskan Native cultural group, and to test some hypotheses developed in previous research with school-age American Indian children regarding major factors which would be expected to effect scoring profiles in various ways.

In the investigation reported here, we have analyzed test scores and parent interview data for 40 Alaskan Native 5 -year-olds living in the Ketchikan-Metlakatla area of Southeast Alaska in 1984. The focus of this project was (1) to determine normative data for this population of young Native children, and (2) to examine the environmental factors associated with variability in performance on the different subscales of the WPPSI. 
CHAPTER II

METHOD

\section{Subjects}

Subjects were forty children living in the vicinities of Ketchikan $(\underline{n}=27)$, and Metlakatla $(\underline{n}=13)$, Alaska. Ketchikan is a city of 14,000 where Natives comprise a minority of less than $30 \%$. Metlakatla is a native community on the Annette Island Indian Reservation and is accessible from Ketchikan via the Alaska State Ferry System and commercial seaplane operators. The subjects of this study may not be representative of the entire population of Southeast Alaskan Native children, which is widely dispersed accross a vast geographic area with many remote, isolated villages and seasonal patterns of family movement. Ketchikan and Metlakatla both have established, year-round economies with a great deal of seasonal (summer) employment related to the commercial fishing industry. Data collection for this study was conducted during the summer months of June, July, and August.

Subjects were identified from local birth records, tribal enrollments, and participation in early childhood programs. All potential subject families which could be contacted consented to participate in the study and the age range was expanded in the course of data collection to reach the targeted sample size of 40. The target age of $51 / 2$ was selected in order to maximize 
the psychometric value of scores by avoiding the floor and ceiling effects which are inherent in the score distributions for 4- and 6-year-olds, (Sattler, 1982). The mean age of the 23 boys and 17 girls to whom the WPPSI was administered was 5.5 years with a range of 1.25 years ( 4.75 to 6.0 years). All of the subject children were tribally enrolled or eligible for Tribal enrollment in organizations representing the Tlingit, Tsimshean and Haida Nations. As such, they are descendents of one of the richest cultural traditions in North America. The Native peoples of the Northwest coast region developed a complex social organization based upon strong extended kin relations among a variety of clans. Ceremonial, artistic, architectural, and familial traditions flourished in a land abundant with sea and timber resources. Many of these traditions have continued into the present in modified form as a firm basis of identity for many Alaskan Natives.

The mean Native Blood Quantum ${ }^{1}$ of the subjects in this study was .511 and ranged from .125 to 1.0 (full native). Twenty of the children had a blood quantum within the range .125 to .385 while the other 20 ranged from .5 to 1.0 with an overall modal blood quantum for the entire group of $1.0(\underline{n}=9)$.

Procedure

Subjects were administered a11 12 subtests of the WPPSI in accordance with the standardized instructions contained in the Manual (Wechsler, 1967). The examiner had received graduate level training in the use of these instruments and had previously 
administered the WISC-R to American Indian children in a National Institute of Mental Health sponsored study.

In order to obtain an optimal performance from each child, care was taken to establish a relaxed, supportive, and nonthreatening rapport. The examiner paid particular attention to sociolinguistic discourse rules governing interactions among Northern native peoples (Scollon \& Scollon, 1981). Children were allowed to finish tasks even though credit could no longer be earned due to expiration of time limits. The examiner spoke softly and listened carefully, avoiding interruptions and the necessity to ask children to repeat verbal responses. Children were allowed ample time to respond to questions and the examiner avoided any prompting with eye- or physical-contact, providing the subject child with personal space and autonomy. Smiles and gentle verbal reinforcement were used to encourage the child's performance. These procedures were utilized with all participants in order to eliminate any score variablity due to variability in Examiner behavior. Such factors were shown to significantly affect scores on the WISC-R with Papago Indian children while the ethnicity of the examiner did not (Conrad, 1974).

A parent of each child responded to a standardized interview form providing data on family size, demographics and health history. (Copies of parental consent and interview forms are contained in the Appendix) All data was coded for computer analysis using Version 9 of SPSS, The Statistical Package for The Social Sciences (Nie, et al, 1975). 


\section{CHAPTER III}

\section{RESULTS}

\section{Score Data}

The score distributions produced by this group of children contained less variability than the standardization samples described in the test manual. This is likely due to the homogeneity of the sample and the highly standardized administration procedures described earlier. The raw scale scores for the standardization groups were converted to standard scores with a mean of 100 and a standard deviation of 15 (the "average" or "normal" range is defined as a score within one standard deviation of the mean). Observed IO scores for our sample are presented in Table I.

\section{TABLE I}

MEAN IQ SCORES, STANDARD DEVIATIONS, MEDIANS \& RANGES FOR STUDY SAMPLE $(N=40)$

\begin{tabular}{lccccc}
\hline IQ & Mean & S.D. & Median & Minimum & Maximum \\
\hline Performance & 108 & 13 & 104 & 85 & 138 \\
Verbal & 100 & 11 & 99 & 77 & 119 \\
Full Scale & 104 & 11 & 104 & 83 & 130 \\
\hline
\end{tabular}


These scores are consistent with the findings of McShane and Plas (1984) who state that a significant elevation of the performance over the Verbal IQ of eight to nineteen points can be considered typical for the Indian Child. As expected, the difference between the Verbal and Performance means was significant, $\underline{t}(39)=-3.87, p<.001$.

We were particularly interested in the means of subtest scores recategorized according to the Bannatyne (1968) scheme. For Subtests, the standardization groups have a standard score mean of 10 with a standard deviation of 3 . Recategorized scores for our sample were as shown in Table II.

\section{TABLE II}

MEANS OF SUBTESTS RECATEGORIZED ACCORDING TO BANNATYNE (1968)

\begin{tabular}{lcrrrrr}
\hline $\begin{array}{l}\text { Bannatyne } \\
\text { Subscale }\end{array}$ & $\begin{array}{c}\text { Component }^{3} \\
\text { Subtests }\end{array}$ & Niean & S.D. & Median & Min. & Max. \\
\hline Spatial & PC, BD, GD & 11.48 & 1.9 & 11.28 & 8 & 16 \\
Sequential & Sn, Ar, AH & 9.40 & 1.8 & 9.39 & 4 & 12 \\
$\begin{array}{l}\text { Conceptual } \\
\text { Cm, Sm, V }\end{array}$ & 10.27 & 2.0 & 10.00 & 6 & 14 \\
$\begin{array}{l}\text { Acquired } \\
\text { Knowledge }\end{array}$ & I, Ar, V & 9.28 & 1.8 & 9.61 & 7 & 13 \\
\hline
\end{tabular}

These results are again consistent with those of McShane and Plas (1982a) who suggest superior development of Spatial processing skills in young Indian children. All of the between 
subscale differences were significant ( $p<.01)$ except the Sequential-Acquired Knowledge difference, $\underline{t}(39)=-1.89, p>069$.

In order to assess the validity of the Kaufman (1975) factor analytic results with this group, all 12 subtest scores were subjected to several factor-analytic procedures ${ }^{2}$ with oblique rotation utilized to arrive at terminal solutions. Each procedure loaded the same subtests together, yielding the 3 factor solution shown in tables III and III-A.

\section{TABLE III}

FACTOR STRUCTURE (CORRELATION COEFFICIENTS) DERIVED FROM PRINCIPLE COMPONENT ANALYSIS WITH OBLIQUE ROTATION

\begin{tabular}{llll}
\hline Subtest & Factor 1 & Factor 2 & Factor 3 \\
\hline Information & -.061 & $.783^{*}$ & -.133 \\
Animal House & -.377 & .249 & $-.952^{\star}$ \\
Vocabulary & -.450 & $.663^{*}$ & -.461 \\
Picture Completion & $-.485^{\star}$ & .141 & -.256 \\
Arithmetic & $-.546^{*}$ & .420 & -.376 \\
Mazes & $-.924^{*}$ & .103 & -.236 \\
Geometric Design & $-.599^{*}$ & .226 & -.512 \\
Similarities & -.395 & $.453^{*}$ & -.156 \\
Block Design & $-.736 *$ & .396 & -.313 \\
Comprehension & -.436 & $.911^{*}$ & -.487 \\
Sentences & -.204 & $.699^{*}$ & -.280 \\
Animal House Retest & -.318 & .391 & $-.822^{*}$ \\
\hline \% of variance & 63.0 & 21.8 & 15.2 \\
\hline
\end{tabular}


TABLE III-A

MEANS OF SUBTESTS RECATEGORIZED ACCORDING TO THE OBSERVED THREE FACTOR SOLUTION

\begin{tabular}{lllllll}
\hline Factor & $\begin{array}{c}\text { Component }^{3} \\
\text { Subtests }\end{array}$ & Mean & S.D. & Median & Min. & Max. \\
\hline $\begin{array}{l}\text { Performance } \\
\text { Spatial (1) }\end{array}$ & $\begin{array}{l}\text { PC, Ar, Mz, } \\
\text { GD },\end{array}$ & 11.1 & 1.8 & 11.0 & 8 & 15 \\
$\begin{array}{l}\text { Verbal- } \\
\text { Semantic (2) }\end{array}$ & $\begin{array}{l}\text { I, V, Sm, Sn } \\
\text { Cm, }\end{array}$ & 9.8 & 1.9 & 9.9 & 5 & 13 \\
$\begin{array}{l}\text { Sequential (3) } \\
\text { Coding (3H, AHr }\end{array}$ & 9.6 & 2.4 & 9.1 & 4 & 15 \\
\hline
\end{tabular}

The three factors observed for this group resemble those identified by Kaufman (1975) based on WISC-R standardization group data for each age group from 6 to 16 years. However, Sattier (1982) points out that the 3rd factor (labeled Freedom from Distractability in Kaufman's Analysis) emerges on the WISC-R, but not on the WPPSI. Sattler (1982, p. 212) concludes that "sustained directed attention is a part of every subtest at younger ages and only emerges as a separate factor for older ages." Our results may suggest that such a 3rd factor is a well differentiated variable for this population of young children. The Performance-Spatial factor was the most clearly differentiated of the three factors as determined by Eigen values, with the Verbal-Semantic factor ranked second. The factor 1 mean for our sample differed significantly from the 
factor 2 mean, $\underline{t}(39)=3.95, p<.001$, and al so from the factor 3 mean, $\underline{t}(39)=4.14, p<.001$, while the factor 2 and factor 3 means were equivalent, $\underline{t}(39)=.53, p>.597$.

\section{Parent Interview Data}

The standardized interview collected data regarding environmental and other variables which have been linked in other studies to scoring profiles on the WISC-R (McShane \& Plas, 1980, 1984). Interview questions were related to Tribal affiliation, "Indian blood quantum", family composition and mobility, participation in early childhood programs, instances of upper respiratory $i l 1$ ness, auditory and visual deficits, and family identification with/participation in native culture. Observational data consisted of the child's preference (left or right) for use of one hand, eye, and foot, and a coding of the child's physical appearance (based upon hair, eye, and skin color) as either native, caucasian, or other. Of 26 ordinally coded interview variables, significant correlations with WPPSI score data existed for only eight. 
The variable Family Size was normally distributed for the 40 cases with a mean of 4.9 (including subject child) and a range from 2 to 9. Family Size was the strongest predictor of overall performance. Increasing Family Size was significantly associated with lower IQ, factor and individual subtest scores (Full Scale IQ $\underline{r}=-.46, p<.002)$.

A stepwise multiple regression using 7 interview variables as predictors ranked Family size as the most significant predictor of Full Scale IQ, Performance IQ, Bannatyne Spatial, and Performance-Spatial Factor 1. For all other subscale scores, Family Size was among the top 2 predictors. One exception was Visual-Sequential Factor 3, for which Family Size followed sex (1), child Indian blood quantum (2), and family geographical spread (3).

\section{Child Indian Blood Quantum}

The subject child's Indian Blood Quantum (CIBQ), used for Tribal enrollment purposes, is an index of each child's "degree of Indianness" based upon that of his/her parents. A child with only one Indian parent could have a CIBQ value of up to .5. If that parent was less than full Indian, the CIBQ would be only one-half of the parents, and in our sample ranged down to .125 . A CIBQ of 1.0 would necessitate a full Indian blood quantum of 1.0 from each of both parents. There were 9 such children in our sample.

In the stepwise multiple regression ana?ysis, CIBQ was 
among the top 2 predictors for Bannatyne Sequential, VerbalSemantic Factor 2, and Sequential Coding Factor 3 scores. For Fuli Scale IQ and all remaining subscale scores, CIBQ was among the lowest ranked predictors.

Two independent groups within our sample consisted of those subjects with $\mathrm{CIBQ}<5 \quad(\underline{n}=20)$ and those with $C I B Q \geq 5 \quad(\underline{n}=20)$. There was no difference in mean family size between the high and the low Indian blood quantum groups. These groups did, however, generate significantly different mean scores on 6 subtests (See Table IV), and in 7 of 10 classified scores shown in Table $V$.

\section{TABLE IV}

SUBTEST SCORE MEANS WHICH DIFFERED SIGNIFICANTLY $(p<.05)$ BETWEEN INDEPENDENT CHILD INDIAN BLOOD QUANTUM GROUPS $(N=40)$

\begin{tabular}{|c|c|c|c|c|c|}
\hline \multirow{2}{*}{$\begin{array}{l}\text { Subtest } \\
\text { Animal House }\end{array}$} & \multicolumn{2}{|c|}{$\frac{\text { Child Indian Blood Quan. }}{<.5(\underline{n}=20) \geq .5(\underline{n}=20)}$} & \multicolumn{3}{|c|}{ Significance Level } \\
\hline & 10.7 & 8.5 & -3.01 & 38 & .005 \\
\hline Vocabulary & 11.0 & 8.8 & -2.84 & 38 & .007 \\
\hline Arithmetic & 10.5 & 9.0 & -2.86 & 38 & .007 \\
\hline Comprehension & 11.5 & 9.4 & -3.29 & 38 & .002 \\
\hline Sentences & 9.9 & 8.5 & -2.22 & 37 & .033 \\
\hline $\begin{array}{l}\text { Animal House } \\
\text { Retest }\end{array}$ & 8.9 & 10.4 & -2.06 & 38 & .046 \\
\hline
\end{tabular}


TABLE $V$

MEAN CLASSIFIED SCORES FOR INDEPENDENT CHILD INDIAN BLOOD QUANTUM GROUPS AND SIGNIFICANCE LEVELS OF DIFFERENCES

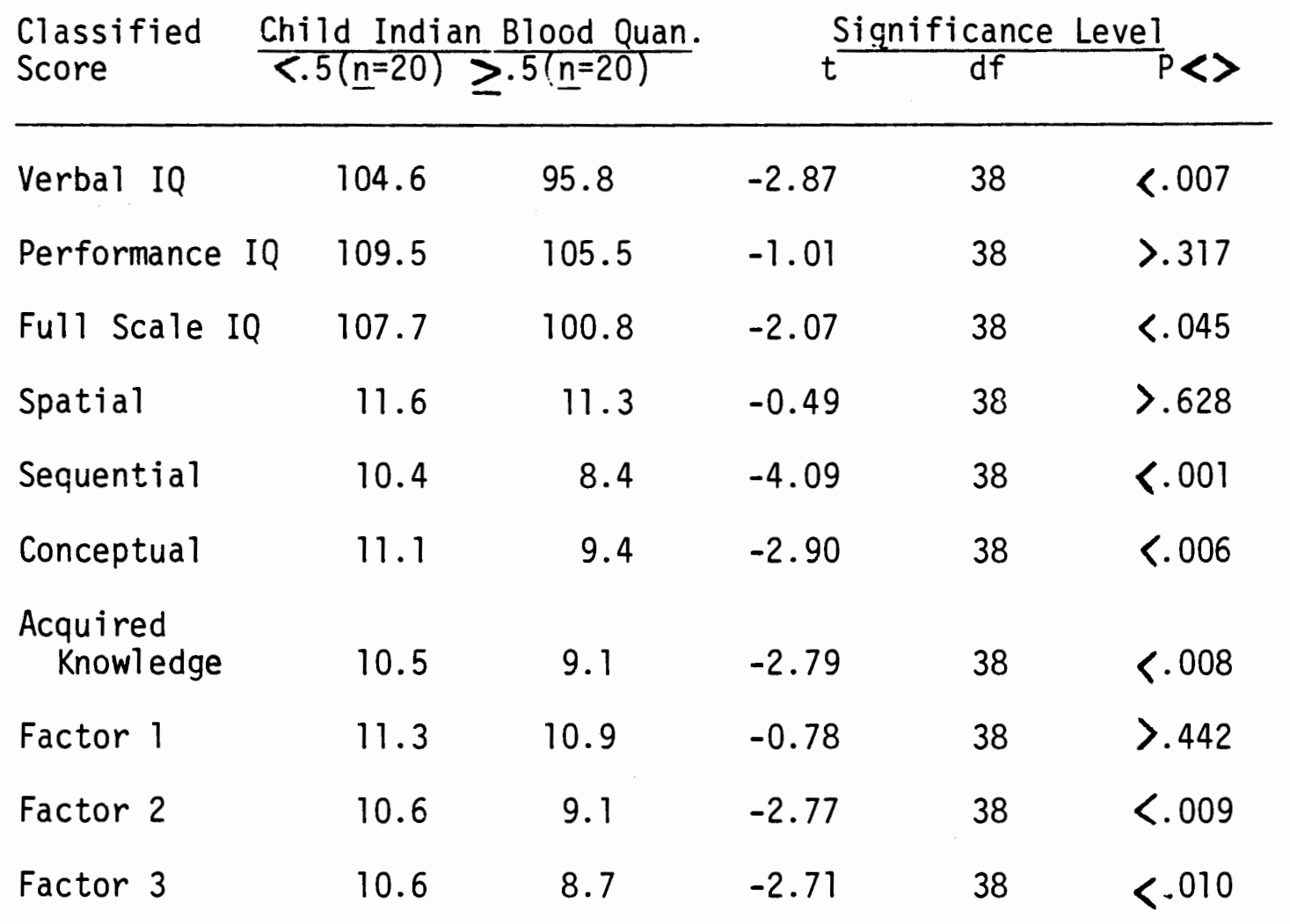

Child Physical Characteristics

While no effort was made to assess inter-observer reliability, it was fairly easy to differentiate children with an overtly native visual appearance from those with an overtly caucasian or other non-native appearance. The variable Chiid Physical Characteristics (CPC) was dichotomously coded and had significant relationships with most of the same scores that related to Child Indian Blood Quantum (CIBQ). Increasing CIBQ was associated with increasing 
frequency of Native CPC, $\quad \underline{r}=.67, p<.001$, as wel1.

The children with observed native (Indian) CPC numbered twenty-six while the remaining children with non-native CPC numbered 14. The mean scores of these 2 independent groups were significantly different $(p<.05)$ on the same subtests and scales so differentiated by CIBQ ( 1 isted in Tables IV \& V), with the one exception of Full scale $1 Q, \underline{t}(38)=1.56, p>.127$.

In the stepwise multiple regression analysis, CPC was the first ranked of 7 predictors for Verbal IQ, Conceptual, and Acquired Knowledge Scores, and ranked third, preceded by CIBQ (1) and Family Size (2), as a predictor of Verbal-Semantic Factor 2 scores.

\section{Gender}

Girls scored significantly higher than boys on Animal House, $\underline{t}(38)=-2.88, p<.007$, on the Animal House Retest, $\underline{t}(38)=-3.25, p<.002$, on the Sequential Subtest mean, $\underline{t}(38)=-2.14$, $p<.039$, and on the Sequential Coding Factor 3 mean which was 10.9 for girls and 8.7 for boys, $\underline{t}(38)=3.3, p<.002$. In the stepwise multiple regression, Gender was the first ranked of 7 predictors of Sequential Coding Factor 3 scores, and ranked fourth as a predictor of the Sequential subtest mean.

\section{Family Geographical Spread}

In the stepwise multiple regression analysis, Family Geographic Spread was the second ranked of 7 predictors (preceded by Family-Size) for Performance IQ, Spatial, and 
Performance-Spatial Factor 1 scores. Increasing geographic dispersion of the child's kin was associated with lower Performance IQ, $\underline{r}=-.36, p<.011$, Spatial, $\underline{r}=-.33, p<.017$, and PerformanceSpatial Factor 1, $r=-.30, p<.029$ scores. The mean Performance IQ score for the 29 subjects whose family extended beyond the Southeast Alaska/British Columbia (Northwest Coast) Region was 105 and differed from the mean of 115 for the 11 subjects whose kin were all residing in the Northwest coast region, $\underline{t}(38)=-2.34$, p<.024.

Parent Report of Orientation to Traditional Native Culture

When asked to rank the importance (in terms of what their child should learn) of traditional native culture, and the contemporary modern culture, the majority of parents $(\underline{n}=14)$ rated them as being of equal importance. Of the remaining 26 parents, 13 believed that traditional ways were of greater importance and 13 stated that the ways of the larger majority culture were of greatest. importance.

This data (coded on a five point Likert Scale) was significantly correlated with the mean of Animal House, and Animal House Retest (Sequential Coding Factor 3) scores. Increasing orientation toward Native culture (and away from majority culture) was associated with lower scores for these subtests, $r=.31, p<.027$. In the stepwise multiple regression analysis, this data was selected as the third ranked of seven predictors of Performance IQ, Bannatyne Spatial, and 
Performance-Spatial Factor 1 scores, preceded in each case by

Family Size (1) and Family Geographic Spread (2).

Participation in Native Culture

21 parents reported that their families did not participate in any native cultural activities (although many said that they wished they did or planned to do so when they could find the time or when the children were older). The remaining 19 stated that they (and/or their children) were regularly active in groups such as the Alaska Native Sisterhood or the Cape Fox Dancers.

There was a significant point-biserial correlation of "yes" (participation responses) with lower Sequential scores, $\underline{r}=-.32, p<.023$, but the stepwise multiple regression analysis indicated that the variablility in mean Sequential scores was best accounted for by Child Indian Blood Quantum (1), Family Size (2), Geographic Family Spread (3), and Gender (4).

\section{Early Childhood Programs}

The greatest child enrollment was in the "Home-Base" early childhood program operated by the Ketchikan Indian Corporation (KIC). Other programs in which children had been enrolled were preschools, Head Start, and Kindergarten. KIC Home Base, a developmental enrichment program, utilized home visitors to instruct parents of infants and young children on the subiect of developmental stages and the range of behavior which typifies those stages. Parents received materials and suggestions for play and other activities designed to provide nurturance and 
stimulation in order to enhance sensory and emotional development while also teaching parenting skills.

Parents who had participated in this program with their children made highly positive remarks about its benefits to their child. Of the 27 children from Ketchikan, 13 had been involved in KIC Home Base for a year or more. Participation was associated with higher scores on the Similarities subtest, $r=.36, p<.03$, the Block Design subtest, $\underline{r}=.43, p<.012$, and the Mean of Bannatyne Spatial subtests, $r=.32, p<.05$.

Other Parent Interview Variables

Significant intercorrelations among some of the interview variabies indicated some trends of interest. Reported family gatherings were associated with study site, with more such gatherings reported in Metlakatla than in Ketchikan, $r=.40, p<.005$. Family gatherings also increased with increasing Indian Blood Quantum, $\underline{r}=.49, p<.001$. Increasing Indian Blood Quantum was also associated with participation in native cultural activities, $r=.31, p<.025$. Girls were reported to have had fewer episodes of ear infections than boys, $\underline{r}=-.37, p<.009$. Decreasing enroliment in preschool programs was associated with increasing numbers of older siblings, $r=.32, p<.021$. Reported family gatherings were associated with increasing Father Indian Blood Quantum $\underline{r}=.49$, p.<001. The fathers interviewed were more likely to report a traditional cultural orientation, $\underline{r}=.32, p<.022$, and participation in native culture, $\underline{r}=.31, p<.024$. Two parent families reported 
more children than single parent families, $r=.52, p<.001$. Increasing instances of local household relocations were associated with single parent families, $\underline{r}=-.31, p<.026$. Increasing family size was associated with fewer local household relocations, $r=-.30, p<.03$. 
CHAPTER IV

\section{DISCUSSION}

One goal of this study was to assess the relationships of certain environmental variables with the young child's learned proficiency in certain cognitive processing skills (as observed in performance on the various 12 subtests of the WPPSI). Family Size was the most relevant such variable. Increasing Family Size was significantly associated with lower scores on all individual subtests and all classified scores derived from those subtests, including Full Scale IQ. This robust relationship apparently applies across cultures and has been explained by Zajonc (1976) as a result of the level of sophistication of the child's intellectual environment. Increasing numbers of siblings (and decreasing rank in birth order) result in increasing interaction with immature siblings and decreasing interaction with mature adults. This effect of a "diluted" family intellectual environment has been observed in European and American populations and was the most salient environmental variable relating across the board to scores within this Alaskan Native sample.

Some of the other environmental variables manifesting significant relationships with scores further emphasize the importance of the early socio-familial environment to the acquisition of adaptive cognitive skills. Another important 
variable for this population was the geographical dispersion of the child's immediate kin. Increasing dispersion of kin, particularly beyond the boundaries of the northwest coast (indigenous) region was associated with decreasing competency in those skill areas which are most distinctly Indian and which have been regarded as the most valid indicators of Indian scholastic aptitude: the Performance-Spatial subtests tasks. Closer proximity of kin appears to significantly enrich the child's cognitive developmental path in culturally appropriate ways.

Two variables, Indian Blood Quantum and Physical Appearance were significantly correlated with one another, and with a number of scores, notably those representing competency in Sequential and Verbal-Semantic skill areas which are most salient within the majority (European-American) culture. Skills in these areas increased significantly as Indian Blood Quantum and the observed frequency of Indian physical characteristics decreased. These latter two variables may be a fairly reliable indicator of Indian self-identity (among adults) since increasing parental Indian Blood Quantum was associated with increasing frequency of reported participation in organized native culture. These same two variables appear also to relate to the extended family relationships characteristic of Indian culture, since increasing Indian Blood Quantum was also significantly related to increasing frequency of family gatherings. Conversely, it could also be said that increasing parental identification with the majority culture is associated with increased independence from extended $k i n$, decreased 
participation in organized Native culture, and increased competency in the cognitive skills most valued within the majority culture.

It might be worthwhile to note that adults interviewed were all very aware of their child's and their own Indian Blood Quantum and from what familial relationships these figures were derived. All self-reports of tribally enrolled Alaskan Natives were in agreement with the actual tribal enrollment figures. The effects of parental self-identity were also reflected in Orientation to Traditional (versus majority) culture which was associated both with increasing Performance-Spatial scores and decreasing Sequential-Coding scores.

The relationship of Gender to Sequential scores (girls score higher than boys) is not clear al though it may be specific to some behavioral gender role differentiation within this population. Girls may, at an early age, be expected to be more aware than boys of the sequential formulas associated with household tasks. The greater frequency of episodic ear infections among boys may indicate that girls spend less time outdoors (in the cold, wet climate characteristic of this region) than do boys. While most of the early childhood education programs represented by participants in this study have no relationships to score data, this may simply be a result of the small representation of all but one as a proportion of our sample. The most represented program in this sample, the Ketchikan Indian Corporation's Home Base program, was unique in its focus upon the quality of the parent-child relationship. Parent-child 
participation in this program was significantly associated with higher performance on two subtests which measure the use of Spatial processing skills: Block Design and Similarities. While Similarities loaded primarily as a Verbal-Semantic subtest, it also had a strong secondary loading on the Performance-Spatial factor. This dual factor dependence of the Similarities subtest has led other investigators to identify it as a predominantly Spatial processing task. In the context of the Luria-Das Simultaneous-Successive (SpatialSequential) Model, WISC-R subtest groupings included Similarities under Simultaneous processing tasks (Naglieri, et al, in press). The focus of the KIC Home Base program, which is designed and run by the Ketchikan Tribal Government, is the quality of a healthy and nuturant parent-child relationship. Participation in the program appears to enhance competency in areas of cognitive processing which are the most culturally valued within the native population.

It would appear from the data collected in this study that there is indeed a somewhat typical wechsler scoring profile for indiginous American children and that the manifestation of this pattern is more closely associated with children who have more than .5 Indian Blood Quantum and who's parents express greater identification with native culture. More precisely, the typical Indian pattern which is most characterized by a significant elevation of Spatial over Sequential skill proficiency is closely related to social environmental factors which typify characteristic patterns and traditions of native culture. These would be represented by 
all of the variables just described except for family size which apparently affects the acquisition of skill competency the same way in all groups.

In many school-age children, the manifestation of this pattern may lead well meaning learning specialists to incorrectly infer a developmental deficit or learning disability, particularly when Verbal-Semantic skills are also low. If the WISC-R and WPPSI were "norm-referenced" to the performance of Indian children, the performance norms of majority culture children would appear unusual, reflecting superior development of Sequential skills and underdevelopment of Performance-Spatial skills.

The difference is such that members of either group may regard those of the other group as having a notable deficit in the cognitive coding and socio-linguistic skills most valued by their own cultural group. The phenomenon of Ethnocentrism has been defined as a syndrome (Brewer, 1979) involving mutually reinforcing interactions among attitudinal, ideological, and behavioral mechanisms which serve to perpetuate intergroup conflict, competition, and hostility. Scollon and Scollon (1981) have shown through sociolinguistic analysis how negative cross cultural stereotypes are inaccurately generated based upon cultural differences in the timing of speech, politeness structures, semantic referencing and non-verbal behavior. In educational settings, the consequences of such stereotyping can relate directly to student achievement when teachers spontaneously conclude that Indian students are reticent and difficult to 
work with because of a disadvantaged environment (McShane and Plas, 1982a). The inaccurate perceptions of non-Indian teachers can determine their expectations for performance among Indian children which may in turn be communicated to the student both verbally and non-verbally as personal attributions. The selfexpectancies of students and their own actual performance in school settings can be significantly effected by such attributions (Wi kinson, 1981).

The benefits to school children of education in a setting which recognizes the unique strengths of individuals within the context of culture has been described el sewhere (Mohatt \& Erickson, 1981, Philips, 1972). Progressive steps to incorporate cultural understanding into educational curricula have been rare. The public school system of Portland, Oregon has undertaken a pioneering effort in implementing Multicultural Education and has developed core curriculum materials dealing with each of the geocultural groups represented in its population, including Europeans, Chinese, Vietnamese, Blacks, Chicanos, and American Indians. Such curricula aim to develop an awareness in teachers and students of their own and other cultural backgrounds in terms of their historical social history and unique socio-cultural development. The development of such awareness seems an appropriate step in fostering a pluralistic understanding of humanity. There certainly is reason for parents and others to seek and demand such education for their children. Apart from the development of mainstream curricula, however, it is clear that the process of assessment for exceptional 
students must take into account cultural differences related to culture-appropriate norms for standardized testing. The development and understanding of such norms can mean the difference between inequitable and invalid versus more reliable and appropriate educational assessment.

Cognitive Factor Structure of Southeast Alaskan Native 5-year-olds

The 3-Factor scheme described by Kaufman (1975), as observed in all of the standardization groups (age 6-16) appears to be observable in certain populations of native children, and perhaps mainly younger age groups, but should not be ruled out as a possibility among Indian groups. When it does occur, as in the early childhood sample analyzed here, it can be described as both similiar and different compared to the Wechsler factor structure of majority-culture school-age children observed by Kaufman.

In our data, the same (parallel) or closely related subtests loaded into the same factor groupings. A major difference was the main or strongest of the three factors, which for our sample was the Performance, or Perceptual-Organization factor, rather than the Verbal one. This factor was called Performance-Spatial because it is the subtests within these categories that have been consistently the highest reported across Indian geocultural groups (Dana, 1984). The Verbal-Semantic factor dominates in subtests which are all both verbal in content and presentation and also involve culturally assumed semantic structures.

Work in developmental semantics and psycholingustics would 
support the conclusion of Dana (1984) that verbal skills may be interpreted as an aptitude-test equivalent for estimation of a child's readiness to participate in the pervasive semantic fields 4 which constitute structural underlying assumptions in majority culture classrooms. The complexities of the varied elements of semantic word-meaning relations (as well as their interaction with social context and non-verbal behavior) provide many avenues for variability in meaning relations of language:

A word is a particular sound pattern and the meaning a language user attaches to it is simply that-attached to it by the language user... All meaningful words have intension (meaning), but not necessarily extension (external referents)... The relation of a word to $i$ ts referent (or meaning) is indirect and mediated by the mind... The lack of a constant relation between a word and its meaning is probably the usual case... (Kuczaj, 1982, pp. 100-101).

The plasticity of word meaning relations makes possible the variations in semantic meaning which can exist within the same language as a result of cultural differences. Scollon and Scollon (1981) describe a system of semantic referencing which is characteristic of northern Athabascans whether they speak in English or Athabascan. The semantic fields of Athabaskan speakers, as well as their sociolinguistic discourse patterns are significantly different from those used by majority-culture English speakers and can be regarded as pervasive expressions of social organization and culture. These differences are a major obstacle to successful interethnic communication and illustrate the consequences of evaluating all but highly acculturated Indian children on the 
basis of their verbal responses (or lack thereof) to linguistic stimuli which contain semantic meaning characteristic of another culture.

The component subtests derived from Factor Analysis of the Southeast Alaska scores are presented in Table VI along with the component WISC-R subtests of the majority culture standardization groups.

The Verbal-Semantic factor differs from the Verbal Comprehension factor only in its inclusion of the Sentences subtest. While sentences may appear to be a memory task like Digit Span, it features one thing that Digit Span does not, semantic and syntactic structure, the comprehension of which enhances memory. Performance on this subtest was clearly related to majority-culture language skills in which this group as a whole was quite competent.

The Arithmetic subtest of the WPPSI begins quite differentiy than does the Arithmetic subtest of the WISC-R and loads on the Performance-Spatial rather than on the Sequential factor. Das and Jarman (1979) note that simultaneous and successive processes are used at the individual's option depending upon how he or she perceives the task. The WPPSI subtest begins with visual stimuli such as pictures and blocks accompanied by questions dealing with quantitative concepts (i.e., longest, biggest, most). These procedures orient the child to Spatial (or Simultaneous) coding which is applied in degrees beyond item 9 , the first purely verbal presentation in this subtest. The WISC-R Arithmetic subtest, by contrast, makes immediate demands upon the sequential coding skills which are 


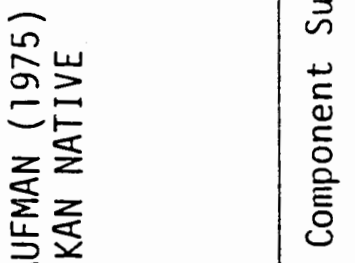
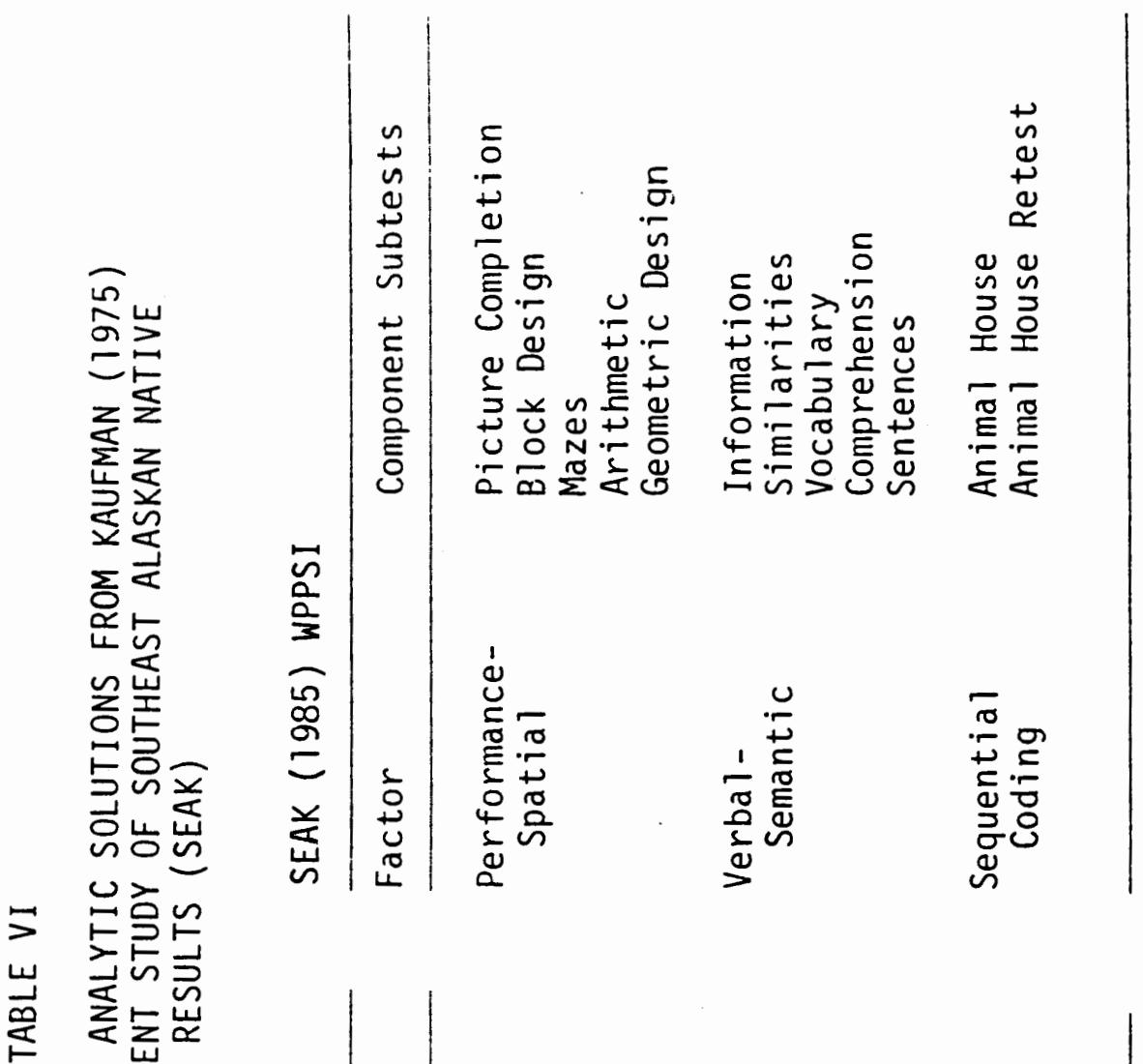

뜸

은뜸슴

还琼高

世

岁

논

5

峁乞

号志

$\vdash$

㟧

岁品

넝

过
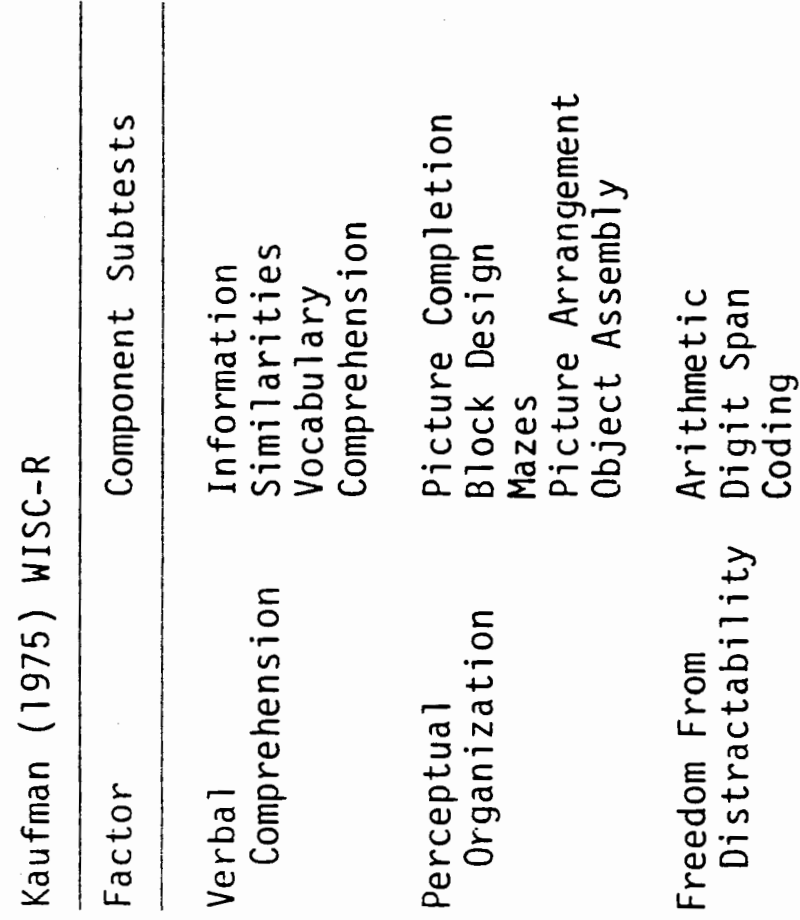

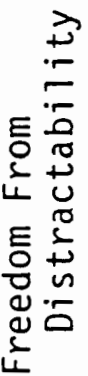


essential to computational competence. The WISC-R subtest is a great deal more like Digit Span than the WPPSI subtest which begins with visual and conceptual, rather than auditory and sequential stimuli.

The coding subtest of the WISC-R is virtually identical to Animal House and involves repeated correct matching. WISC-R Coding uses abstract symbols while WPPSI Animal House uses concrete colors and animal pictures (four pairs). The WISC-R subtest has more combinations and is thus more complex (geared to older children).

A question that arises from the observed factor pattern of this study relates to the evidence of a third (sequential) factor which, according to Sattler (1982, p. 212) should not exist until after the age of Six (among majority-culture children). Our data certainly support the hypothesis of superior development of Performance-Spatial skills in young Indian Children (McShane \& Plas, 1982a). Due to the complementary relationship of Simultaneous (Spatial) and Successive (Sequential) coding processes, is it possible that the differentiation of rudimentary sequential coding skills might be associated with well developed spatial coding skills? We recall the evidence of Suchman and Trabasso (1966) that the selective attention preference of majority-culture (western) children for Color shifts decisively to Form at about age five, presumably as a result of demands for attention to symbols which, once recognized, become the sequentially related elements of written language. We also have cited the evidence of Snart (1978) indicating that among majority-culture children successive processing 
skills emerge between the ages of 6 and 11 as a dominant factor in semantic (deep levels-of-processing) recall tasks. Prior to age six, recall depends primarily on a memory (recognition) factor, while after age 10 and before age 17 a Simultaneous factor becomes most salient in deep-processing recall tasks. While these studies have not been replicated with any Indian groups, it seems possible that a different developmental sequence may exist in Indian cultures, one which differentiates both Spatial and Sequential coding skills at an early age. Investigations such as these conducted with Indian populations could reveal the long term consequences of such fundamental early development of Spatial and Sequential coding skills in some Indian populations. The differential between these two skill areas may change over time and affect the Indian child's readiness for certain learning experiences which are more appropriately timed to the developmental sequence of majority-culture children.

\section{CONCLUSION}

We have attempted to describe some of the conditions under which cognitive modality specialization occurs in early childhood among southeast Alaskan Natives. Das and Jarman (1979, p. 313) point out that "different patterns of modality specificity among different populations are influenced by, or a result of, concommitant patterns of strategic behavior." Certainly a primary determinant of such patterns of strategic behavior (how they are conceived and toward what ends) is culture. Culture refers to those socially transmitted patterns for behavior characteristic of a particular social group. 
An important distinction here is between patterns for behavior and patterns of behavior.

Keesing (1981) defines the overt ecological aspects of culture as a Sociocultural System, that being the unique and adaptive way-of-life-in-ecosystem, or lifeway characteristic of a geocultural group. The Sociocultural System (or pattern of behavior as an environmental adaptation) is the manifest of culture as an Ideational System.

Cultures in this sense comprise systems of shared ideas, systems of concepts and rules and meanings that underly and are expressed in the ways that humans live (Keesing, 1981, p. 68).

Culture in this sense is more than simply expressions of art, architecture, and use of material resources. These expressions change over time and are guided by the Ideational System interacting with environmental impact. The Ideational system is pervasive and underlying, even in the face of rapid changes in the Sociocultural System, as were precipated among most American Indian geocultural groups by the arrival of Europeans in the Americas.

The test instrument used in this study is one of many similar such test batteries which are commonly used in schools to assess the aptitude and achievement of students in order to effectively plan their educational experience. However, many public schools still operate on a system of homogeneous "mainstream" education. 
Students who do poorly in one or several areas of conceptual competency are given a label (i.e., learning disabled) which "entitles" them legally to special education services. The services to which these students are entitled often consist of alternative, vocation-oriented classroom placements where there is no or little expectation for excelling beyond competency in very basic contemporary survival skills. The consequences of this system of dealing with exceptional children (of both majority-and minority-culture background) is often an inequitable loss of human potential.

The two most significant "Agencies of Socialization" for the developing child in today's world are unquestionably the family and the educational system. A third major agency is the peer group which becomes increasingly important as children get older. When the child's primary family experience (in terms of social interaction consisting in part of politeness strategies, discourse patterns and other "participation structures") is greatly incongruent with that existing in the school, interethnic communication problems will arise. To virtually all Indian children, their family is the basis of perceived ties to their native culture while the school is often an immersion in the behavioral ecology of the majority culture. Thus some Indian people will speak about the difficulty and stress of learning to walk through life with a foot in each world. 
Anthropologists have viewed multiculturalism as developing in the wake of urbanism, economic specialization, social stratification, and conquest states. Mu?ticulturalism can be defined as a process by which individuals in a society arrive at shared understandings about things and their expectations of one another. Goodenough (1978) sees multiculturalism as an emergent phenomenon in today's world which characterizes simple as well as complex societies. Multicultural skills are an increasingly important factor in the degree to which individuals are able to coexist and cooperate.

Educational systems have the capacity, and perhaps a responsibility to contribute to an important environment of socializationto-culture for all children. Implementation of interethnic understanding into the educational process has great potential for complementing the bases of cultural identity of American Indian and Alaskan Native children. 


\section{NOTES}

1"Blood Quantum" is not a biological measure but is computed based upon historical $1 / 2$ contributions of parents to their offspring's heredity and is calculated from the recorded or registered blood quantum of native parents.

${ }^{2}$ Procedures used were Principle Component Analysis with iterations, Rao's Canonical factoring, Alpha factoring, and Image factoring.

${ }^{3}$ Subtest abbreviations: $P C$ (picture completion), Ar (Arithmetic), Mz (Mazes), GD(Geometric Design), BD (Block Design, I (Information), $V$ (Vocabulary), Sm (Similarities), $\mathrm{Cm}$ (Comprehension), Sn (Sentences), AH (Animal House), AHr (Animal House Retest).

${ }^{4}$ The Semantic System associated with each language consists of interrelated sets of elements and relations. Semantic fields are "constructed" in terms of such conceptual relations as similarity and dissimilarity, inclusion and exclusion, etc. and are important determinants of (contextualized) meaning attributed to words (Kuczaj, S. 1982). 


\section{SELECTED BIBLIOGRAPHY}

Bannatyne, A. (1968). Diagnosing learning disabilities and writing remedial prescriptions. Journal of Learning Disabilities, Apri1, 1(4), 242-249.

Bannatyne, A. (1974). A note on recategorization of the WISC scaled scores. Journal of Learning Disabilities, May, 7(5), 272-273.

Boorman, S.A. \& Levitt, P.R. (1980). The Genetics of Altruism. New York: Academic Press.

Brewer, M.B. (1979). The Role of Ethnocentrism in Intergroup Conflict. In Austin, W.G. \& Worchel, S. (Eds.) The Social Psychology of Intergroup Relations. Monterey, CA, Brooks/Cole.

Cole, M. \& Bruner, J.S. (1971). Cultural differences and inferences about psychological processes. American Psychologist, 26, 867-876.

Conrad, R.D. (1974) Papago children's intelligence scores as influenced by tester ethnicity, reinforcement, and culture fairness. Unpublished doctoral dissertation (75-4136), The University of Arizona.

Craik, F.I.M. \& TuTving, E. (1975). Depth of processing and the retention of words in episodic memory. Journal of Experimental Psychology: General, $104(3), 268-294$.

Dana, R.H. (1984). Intelligence testing of American Indian children: Sidesteps in quest of ethical practice. White Cloud Journal, July, 3(3), 35-43.

Das, J.P. \& Jarman, R.F. (1979). Coding and planning processes. In Friedman, M.P., Das, J.P., \& $0^{\prime}$ Connor, N. (Eds.). Intelligence and Learning. New York: Plenum Press.

Dickson, J.P. (1981). Introduction: Toward an interdisciplinary conception of children's communication abilities. In Dickson, J.P. (Ed.) Children's Oral Communication Skills. New York: Academic Press.

Eddy, E.M. (1978). The reorganization of schooling: An anthropological challenge. In Eddy, E.M. \& Partridge, W.L (Eds.) Applied Anthropology in America. New York: Columbia University Press. 
Erickson, F. \& Mohatt, G.V. (1982). Cultural organization of participation structures in two classrooms of Indian students. In Spindler, G. (Ed.), Doing the Ethnography of Schooling. New York: Holt, Rinehart \& Winston.

Erickson, F. (1981). Timing and context in everyday discourse: Implications for the study of referential and social meaning. In Dickson, J.P. (Ed.), Children's Cral Communication Skills. New York: Academic Press.

Ertz, H. (in press). Scores among matched pairs of non-Indian and American Indian students who were displaying learning disorders. White Cloud Journal.

Frasure, N.E. \& Entwisle, D.R. (1973). Semantic and sytactic development in children. Developmental Psychology, 9(2), 235-245.

Freedle, R. \& Fine, J. (1982). Prose comprehension in natural and experimental settings. In Rosenberg, S. (Ed.), Handbook of Applied Psycholinguistics. Hillsdale, N.J.: L. Erlbaum \& Associates.

Goodenough, W.H. (1978). Multiculturalism as the normal human experience. In Eddy, E.M. and Partridge, W.L. (Eds.). Applied Anthropology in America. New York: Columbia University Press.

Haber, R.N. (1969). Eidetic images. Scientific American, 220, $36-44$.

Henderson, R.W. \& Rankin, R.J. (1973). WPPSI reliability and predictive validity with disadvantaged Mexican-American children. Journal of School Psychology, 11, 16-20.

Hollii, V:A. \& Kunze, L.H. (1969). Effects of chronic otitus media on language and speech development. Pediatrics, 43(833).

Kaplan, G.J., Fleshman, J.K., Bender, T.R., Baum, C. \& Clark, P.S. (1973). Long terms effects of otitus media: A ten year cohort study of Alaskan Eskimo children. Pediatrics, Oct., $52(4), 577-585$.

Katz, J. (1978). The effects of conductive hearing loss on auditory function. American Speech \& Hearing Association, 20(10), 879-886.

Kaufman, A.S. (1975). Factor analysis of the WISC-R at eleven age levels between $6 \frac{1}{2}$ and $16 \frac{1}{2}$ years. Journal of Consulting and Clinical Psychology, 43, 135-147.

Kaufman, A.S. (1979). Intelligent Testing with the WISC-R. New York: John Wiley \& Sons. 
Kaufman, A.S. (1981). The WISC-R and learning disabilities assessment: State of the art. Journal of Learning Disabilities, Nov., $14(9), 520-525$.

Keesing, R.M. (1981). Cultural Anthropology: A Contemporary Perspective. New York: Holt, Rinehart and Winston.

Krywaniuk, L.W. \& Das, J.P. (1976). Cognitive strategies in native children: Analysis and intervention. The Alberta Journal of Educational Research, 22(4), 271-280.

Kuczaj, S.A. II (1982). Acquisition of word meaning in the context of the development of the semantic system. In

Brainerd, C.J. \& Pressley, M. (Eds.). Verbal Processes in Children. New York: Springer-Verlag.

Lazarus, P.J. (1982). Counseling the native American child: A question of values. Elementary School Guidance \& Counseling, Dec., 83-88.

Luria, A.R. (1968). The Mind of a Mnemonist. New York: Basic Books.

Luria, A.R. (1970). The functional organization of the brain. Scientific American, 222, 66-78.

Luria, A.R. (1980). Higher Cortical Functions in Man (2nd Ed.) New York: Basic Books.

McShane, D.A. \& Plas, J.M. (1980). A review of scores of American Indian children on the Weschsler Intelligence Scales. White Cloud Journal, 1(4), 3-10.

McShane, D.A. \& Plas, J.M. (1982a). Wechsler scale performance patterns of American Indian children. Psychology in the Schools, 19, 8-17.

McShane, D.A. \& Plas, J.M. (1982b). WISC-R factor structures for 0jibwa Indian children. White Cloud Journal, 2(4), 18-22.

McShane, D.A. \& Plas, J.M. (1984). The cognitive functioning of American Indian children: Moving from the WISC to the WISC-R. School Psychology Review, 13(1), 61-73.

Mohatt, G.V. \& Erickson, F. (1981). Cultural differences in teaching style in an Adawa school: A sociolinguistic approach. In Trueba, H.T., Guthrie, G.P., \& Au, K.K. (Eds.), Culture and the Bilingual Classroom: Studies in Classroom Ethnography. Rowley, Mass.: Newbury House. 
Naglieri, J.A., Kamphous, R.W., Kaufman, A.S. (in press). The LuriaDas Successive-Simultaneous Model Applied to WISC-R data. In A.W. Engin (Ed.), WISC-R Handbook, Cuyahoga Falls, Ohio, National Association of School Psychologists.

Nie, N.H., Hul1, C.H., Jenkins, J.G., Steinbrenner, K. \& Bent, D.H. (1975). Statistical Package for the Social Sciences. New York: McGraw Hill.

Ong, w. (1958). Ramus, Method and the Decay of Dialogue. Cambridge: Harvard University Press.

Philips, S.U. (1972). Participant structures and communicative competence: Warm Springs children in community and classroom. In Cazden, C.P., John, V.P. \& Hymes, D. (Eds.), Functions of Language in the Classroom. New York: Teacher's College Press.

Rees, H.J. \& Israel, H.E. (1935). An investigation of the establishment and operation of mental sets. Psychological Monographs, $46(6)$.

Ross-Reynolds, J. \& Reschly, D. (1983). An investigation of item bias on the WISC-R with four socio-cultural groups. Journal of Consulting and Clinical Psychology, 51(1), 144-146.

Ruge1, R.P. (1974). WISC subtest scores with disabled readers: A review with respect to Bannatyne's recategorization. Journal of Learning Disabilities, Jan., $7(1), 48-54$.

Ryan, R.A. \& Spece, J.D. (1978). American Indian mental health research: Local control and cultural sensitivity. White Cloud Journal, 1, 15-18.

Sandoval, J. (1979). The WISC-R and internal evidence of test bias with minority groups. Journal of Consulting and Clinical Psychology, 47, 919-927.

Sattler, J.M. (1982). Assessment of Children's Intelligence and Special Abilities (2nd Ed.), Boston: Allyn and Bacon.

Schubert, J. \& Cropley, A.J. (1972). Verbal regulation of behavior and IQ in Canadian Indian and White children. Developmental Psychology, 7(3), 295-301.

Scollon, R. \& Scollon, S.B.K. (1981). Narrative, Literacy, and Face in Interethnic Communication. Norwood, N.J.: Ablex Publishing.

Scribner, S. \& Cole, M. (1981). The Psychology of Literacy.

Cambridge: Harvard University Press. 
Snart, F.D. (1978): Levels of processing and memory: A developmental approach. Unpublished doctoral thesis. University of Alberta, Edmonton, Alberta, Canada .

Suchman, R.G. \& Trabasso, T. (1966). Stimulus preference and cue function in young children's concept attainment. Journal of Experimental Child Psychology, 3(2), 188-198.

Suchman, R.G. (1966). Cultural differences in children's color and form preferences. Journal of Social Psychology, 70, 3-10.

Wechsler, D. (1967). Wechsler Preschool and Primary Scales of Intelligence: Manual. New York: The Psychological Corporation.

Wilkinson, L.C. (1981). Analysis of teacher-student interaction:

Expectations communicated by conversational structure.

In Green, J.L. \& Wallat, C. (Eds.) Ethnography and Language in Educational Settings. Norwood, N.J.: Ablex Publishing.

Wilson, E.0. (1980). Sociobiology (abridged Ed.) Cambridge: Belknap Press of Harvard University Press.

Witelson, S.F. (1977). Developmental Dyslexia: Two right hemispheres and none left. Science, Jan., 195, 309-311.

Yando, R.M. \& Kagan, J. (1968). The effect of teacher tempo on the child. Child Development, 39, 27-34.

Zajonc, R.B. (1976). Family configuration and intelligence. Science, $192,227-235$. 


\section{APPENDIX}

PARENT CONSENT AND INTERVIEW FORMS 
Dear Parent/Guardian:

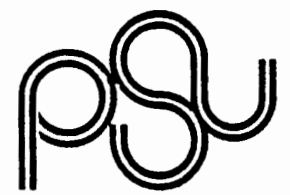

I am gathering information for a study of early childhood learning among Indian and non-Indian children in the Ketchikan area. We are investigating the usefulness of a standardized intellectual skills test and trying to find out something about the strengths with which young children enter school.

PORTLAND STATE o.o. box 751 portland. oregon $503 / 229-3923$ I would like to ask your permission to administer this test to your child,

Your child's scores will make up part of a group of scores. These will be used to compute averages and look for similarities within the group and in comparison with other groups. Names and individual scores will be kept confidential and not reported to anyone. Should anything turn up which might be important to your child's education, I will inform you personally.

This work is being done under the supervision of Gerald D. Guthrie of the Department of Psychology at Portland State University, and Edward $K$. Thomas, Director of Indian Education Programs with the Ketchikan-Gateway Borough School District. If you are willing to help in this project, please indicate so by completing two copies of this form. Please keep one and return the other to Mr. Thomas at the address given below. I will then contact you to arrange a time for testing which is convenient to you. I will also need to ask you a few background questions about your child. It would be particularly important to know if he or she has had any health problems or sickness (such as ear infections) and if he or she speaks or understands a language other than English. These things can affect scores in certain ways which is why it is important to know about them in order to interpret test scores properly.

Thank you for taking the time to read this letter and give consideration to helping out in this project. The results probably will not help your child directly, but we hope to provide some information which will be helpful to teachers working with children in the community.

Tom Turkon

Graduate Student in Clinical Psychology

I am willing to participate in the study of early childhood learning among fiveyear-olds in the Ketchikan area. I consent to my child, taking the Wechsler Preschool and Primary Scales of Intelligence (WPPSI). Child's date of birth: Please contact me at:

(address or telephone number and best time to call)

Date: Signature: (parent or legal guardian)

PLEASE RETURN COMPLETED FORM TO MR. EDWARD K. THOMAS AT THE KETCHIKAN INDIAN CORPORATION, P.O. BOX 6820, KETCHIKAN, ALASKA 99901. TELEPHONE: 225-5158

If you experience any problems resulting from your participation in this study, please contact the Director of Sponsored Research, Office of Graduate Studies and Research, Portland State University, 105 Neuberger Hal1, Portland, Oregon 97207. Telephone:(503) 229-3423 Thank you for your help. 


\section{Sume Information about the WPPSI}

The WPPSI is actually 12 small tests that take about an hour and a half for a child to complete. The time varies because the tests are given at the child's pace without pressure. The child answers questions, draws figures, works with blocks, looks for missing parts in pictures, and does a number of other tasks. These are presented in a frlendly, nonthreatening manner. The interviewer records the child's verbal answers so that the child is not required to do any writing. Children usually have fun doing the tests and of ten want to go back and do parts of them again when the test is finished.

The tests measure the child's skills in areas such as the use of hands and eyes, abllity to remember words they have heard, and learning how to trace a path out of a maze. This test has been adopted widely for use In schools because it does not just measure language related skills. It allows children to demonstrate skills in a wide range of areas that are not language related. For this reason, it is considered to be more useful than other such tests with non-white minority children and children who speak English as a second language. 
(1)

Subject ID \#

CHILD NAME

DATE OF BIRTH

Source of Recruitment:

Parent (s)

Address

Telephone

Contacted (date)

Agreed to par-

ticipate?

Parent Interview; by phone

In person

date_ If arranged, time place

Date arranged for testing child

time

place

If parents refuse to participate, ask if it is okay to ask a few questions. If

yes, Does (child's name) have any problems that you are aware of? (such as hearing or eyesight, lack of speech or coordination)

Do you feel that adequate health services are avallable to you if your children get sick or need eyeglasses?

$\begin{array}{lc}\text { Name of person being interviewed } & \text { RNTERVIEW } \\ \text { chlld } & \text { Relationship to } \\ \text { ChIld's name_ate of birth }\end{array}$

1 Has (child) ever had ear infections where fluld drained out of one or both ears? If YES, how many times has this happenned? once_ twlce___ three___ four or more

Has (ch11d) had colds with coughs, stuffiness or sore throat? If YES, how many times in the last year? once twice three or more

2 Do you or anyone in your home understand or speak a language other than Engl1sh? (1.e. Tling1t, French, Chipewayan, Russian )

If YES, does (ch1ld) understand any of that language? understands some speaks some speaks and understands some What language did (child) learn first? 
ChI1d name

3 Has (child) ever had a hearing (audlometric) examination?

(when, where \& findings)

Has (ch1ld) ever had a visual (eyeslght) examination?

(when, where \& findings)

Does (ch1ld) need to wear eyeglasses or a hearing ald?

no sometimes all the time

(specify)

With or without alds, does (child) have any difficulty seeing or hearing? none some a lot

Is adequate health care avallable to your family when needed?

4 Child's Mother's nationality?

(Alaskan Native, European, American Indian)

Cultural sub-group?

$$
\text { (Ha1da, IrIsh, French, etc.) }
$$

Child's Father's nationality?

Cultural sub-group?

Does (ch1ld) have any favorite televiston programs?

Does your family particlpate in any Alaskan Native cultural events such as celebrations/dances?

Does your family particlpate in any non-native cultural events such as theater, concerts or parades?

In your family, how important is 1 t to keep to ancestral customs and ways? only the traditional ways are important.

traditional ways most important, but must learn modern ways also. traditional \& modern ways are equally important. modern ways most important, but must keep to traditional ways also. only the new, modern ways are important.

5 Has (child) been enrolled in a daycare or preschool program?

If YES, where and for how long?

Where was (ch1ld) born?

(locale, hospltal, home, clinfc)

Has your family made any permanent change in residence since (ch1ld)'s birth?

(number of moves and locations moved from and to) 
Did each move get you closer to or further from family and relatives?

(for each move: closer, further or about the same)

Have one or both parents been employed since (child)'s birth?

(for mother 8 father, occupation(s) and how long at each)

How many adults live within your household?

(relatives or non-relatives to (child): grandparent(s), aunt, uncle, etc.)

Has this situation changed in the last five years?

Do other children live within your household?

(relatives or non-relatives to (child): brothers, sisters, cousins, etc.

please Include ages)

What was the farthest you ever travelled to visit family/relatives?

( Iocation(s) )

Does your family (relatives) get together for re-unions or celebrations?

About how many times in the last five years?

(Include weddings and funerals)

6 If Alaskan Native or American Indian, does (child) have status on any Tribal roles?

(location of registry, blood quantum, etc.)

Interviewer:

date: 